concentration of up to $28 \mathrm{mmol} / \mathrm{l}$ has been shown not to interfere with measurement of serum amylase with this technique (personal communication, Boehringer Mannheim).

In view of his heavy alcohol intake, we considered that our patient may have chronic relapsing pancreatitis in which a normal serum amylase is seen more commonly. This is unlikely, however, as the patient was well between acute episodes, with no abdominal pain. In addition, there is no evidence of pancreatic exocrine insufficiency and no pancreatic calcification or other features of chronic

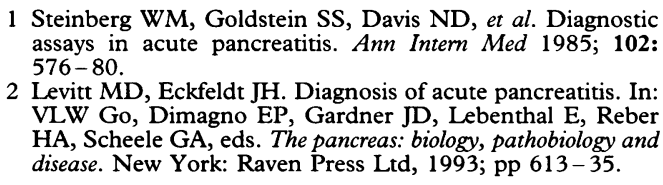
assays in
$576-80$.

2 Levitt MD, Eckfeldt JH. Diagnosis of acute pancreatitis. In: VLW Go, Dimagno EP, Gardner JD, Lebenthal E, Reber HA, Scheele GA, eds. The pancreas: biology, pathobiology and disease. New York: Raven Press Ltd, 1993; pp 613-35.

pancreatitis on plain abdominal radiograph or abdominal CT scan. Finally, our patient has had no further episodes of pancreatitis since effective treatment of his hyperlipidaemia.

\section{Final diagnosis}

Recurrent acute pancreatitis with normal serum amylase concentration.

\section{Keywords: pancreatitis, hyperlipidaemia}

3 Read G, Braganza JM, Howat HT. Pancreatitis - a retrospective study. Gut 1976; 17: $945-52$.

4 Moosa AR. Diagnostic tests and procedures in acute pancreatitis. N Engl f Med 1984; 311: 639-43.

5 Clavien P, Robert J, Meyer P, et al. Acute pancreatitis and normoamylasemia. Ann Surg 1989; 210: 614-20.

\title{
Recurrent dehydration in a young girl
}

\author{
Mohamed Zaki, Essam AR Ismail, Hany M Nadi, Abbas Nour El Din
}

A 50-day-old girl was admitted to hospital because of fever, vomiting and refusal of feeding of four days duration. She was born normally at term to healthy parents who were first cousins. On admission she was dehydrated and weak. Basic blood biochemical investigations were normal apart from a serum sodium of $159 \mathrm{mmol} / \mathrm{l}$. She was given parenteral therapy with subsequent improvement of her condition and she was discharged in good health after a few days. She was readmitted again the following week with fever, lethargy and marked dehydration without an associated history of vomiting or diarrhoea. Investigations showed a serum sodium of $165 \mathrm{mmol} / \mathrm{l}$, potassium $5 \mathrm{mmol} / \mathrm{l}$, chloride $117 \mathrm{mmol} / \mathrm{l}$, bicarbonate $21 \mathrm{mmol} / \mathrm{l}$, urea $5.5 \mathrm{mmol} / \mathrm{l}$, creatinine $52 \mu \mathrm{mol} / \mathrm{l}$, blood sugar $5.2 \mathrm{mmol} / \mathrm{l}$ and serum calcium was $2.2 \mathrm{mmol} / \mathrm{l}$. Complete blood count was normal. Urine was negative for sugar, protein and abnormal sediments with an osmolality of $17 \mathrm{mmol} / \mathrm{kg}$ while that of the serum was 294 . Urine volume passed over a 12 -hour period was $700 \mathrm{ml}$. Administration of intranasal ADDVP did not result in any change in the biochemical values and osmolality of blood or urine. After an initial period of normal psychomotor development it was observed that her progress had begun to lag behind that expected for her age. At the age of seven years her psychomotor development was 12-months retarded and her weight and height were below the third centile for her age. Non-contrast computed tomography (CT) of the head was performed at that age (figures 1 and 2).

\section{Farwania Hospital, Kuwait \\ Department of Paediatrics \\ M Zaki \\ EAR Ismail \\ HM Nadi \\ Department of \\ Radiology \\ A Nour El Din}

\section{Correspondence to}

Dr Mohamed Zaki,

Consultant Paediatrician, Farwania Hospital, PO Box 25850 Safat, Code 13119, Kuwait

Accepted 13 September 1996

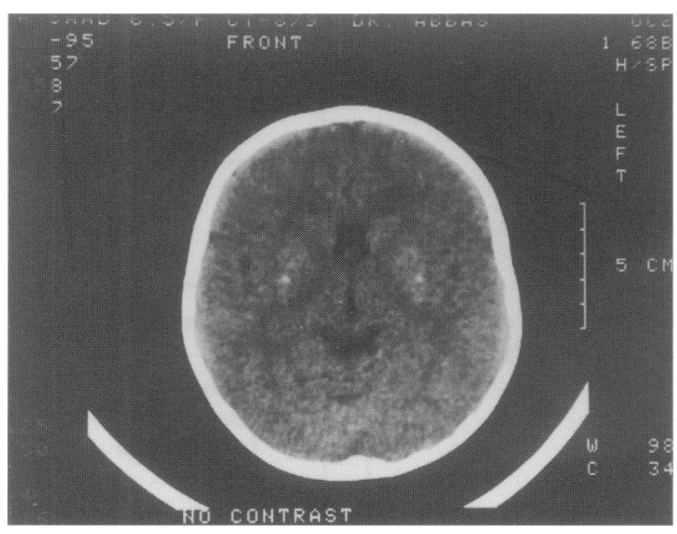

Figure 1 Brain CT scan

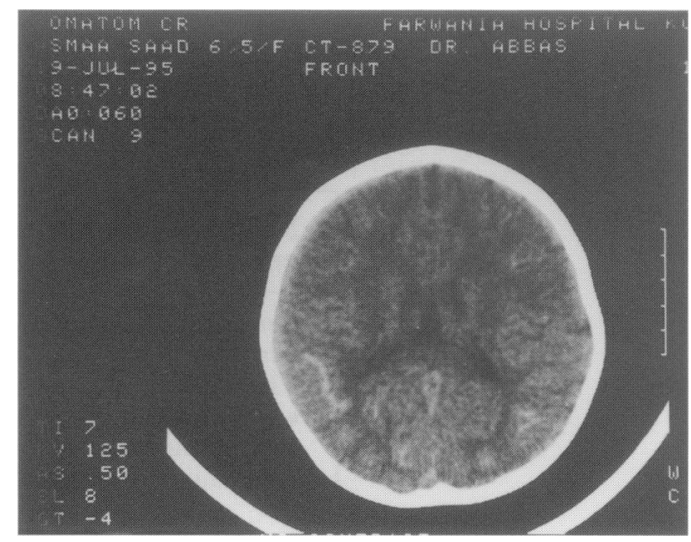

Figure 2 Brain CT scan

\section{Questions}

1 What is the diagnosis?

2 What do the figures show? 


\section{Answers}

QUESTION 1

Nephrogenic diabetes insipidus (NDI). The diagnosis is based on polyuria with a dilute urine, episodes of hypernatraemic dehydration and failure of intranasal ADDVP to increase urinary osmolality, the latter observation also rules out central diabetes insipidus.

NDI can be primary or secondary. Primary NDI usually affects males following an Xlinked mode of transmission (MIM 304800) ${ }^{1}$; females are also affected to a lesser degree by an autosomal recessive pattern (MIM $222000) .^{2}$ In this case, the parental consanguinity and the female sex favour an autosomal recessive inheritance. Secondary causes of diabetes insipidus (renal concentration defects) are shown in box 1. In this case secondary causes were ruled out.

\section{QUESTION 2}

Figure 1 shows bilateral symmetrical calcification of the basal ganglia and figure 2 reveals calcification at the junction between the white and grey matter in the parietal region.

\section{Discussion}

Causes of intracranial calcification in children are numerous (box 2). ${ }^{3}$ Intracranial calcification in children with primary NDI has been recently recognised and reported in a dozen cases. $^{4,5}$ The cause(s) of intracranial calcification in patients with NDI is not exactly known. The postulated theory associates the intracranial calcification with hypernatraemic dehydration based on the following observations: recurrent episodes of hypernatraemic dehydration have occurred in all reported cases of NDI. Dehydration of this type is known to be associated with diffuse microscopic areas of intracranial haemorrhage and microthrombosis $^{6}$ with tissue necrosis which subsequently calcifies. Also in favour of this theory is the finding of calcium deposits within and around blood vessels on brain autopsy of a patient who had NDI and intracranial calcification. ${ }^{7}$

A direct relationship has been observed between the severity of intracranial calcification and the duration of the condition prior to

\begin{tabular}{|l|}
\hline $\begin{array}{l}\text { Nephrogenic defects of urinary } \\
\text { concentration }\end{array}$ \\
\hline $\begin{array}{l}\text { Conditions that affect primarily the action of } \\
\text { antidiuretic hormone on tubular permeability to water } \\
\text { - hypokalaemia } \\
\text { - hypercalcaemia } \\
\text { - drugs (lithium, amphotericin B) } \\
\text { - hereditary (primary) NDI } \\
\text { Conditions that affect primarily the medullary solute } \\
\text { concentration } \\
\text { - chronic renal failure } \\
\text { - obstructive nephropathy } \\
\text { - tubulointerstitial diseases (pyelonephritis, sickle } \\
\text { cell disease, drugs) }\end{array}$ \\
\hline
\end{tabular}

diagnosis and establishment of treatment. ${ }^{3}$ This was noted in our patient where the calcification was mild, probably the result of less frequent attacks of dehydration. Mental retardation has varied from minor memory deficits to profound mental retardation and it has been recognised that the degree of psychomotor retardation is directly proportional to the degree of calcification. Growth retardation is frequent and probably related to caloric deprivation in infants and children who have to drink water in preference to food. Some believe, however, that growth retardation could be an inherent character of the disease.

Treatment of this condition requires a low sodium and protein diet, to decrease the osmotic load that the kidney has to excrete, in addition to a liberal fluid intake, particularly during febrile illness. The combination of thiazide diuretics and indomethacin therapy reduces the urine output dramatically. The mechanism of action of these drugs is not well understood. Diuretics increase the fraction of the filtered sodium chloride and water that is reabsorbed in the proximal tubule and as a result distal tubular flow is decreased. Indomethacin, a nonsteroidal anti-inflammatory agent, reduces renal prostaglandin production.

This case clearly shows that primary NDI may be complicated by intracranial calcification accompanied by psychomotor retardation.

\section{Causes of intracranial calcification in} children

- inflammatory causes: cytomegalovirus infection, toxoplasmosis, neurocysticercosis, HIV infection, herpes simplex encephalitis

- vascular and hypoxic: hypernatraemic dehydration, hypoxic-ischaemic encephalopathy, calcified infarct, arteriovenous malformation

- tumours and dysplasia: calcified astrocytoma, tuberous sclerosis

- endocrine disorders: hypoparathyroidism, hyperparathyroidism

- toxic disorders: carbon monoxide poisoning, lead poisoning, hypervitaminosis $\mathrm{D}$, radiotherapy of leukaemia or tumours

- metabolic and hereditary diseases: mitochondrial encephalopathy, leukodystrophy, biotinidase deficiency, carbonic anhydrase II deficiency

Box 2

\section{Summary points}

- primary NDI is transmitted as an X-linked recessive trait yet in a minority of cases it follows an autosomal recessive inheritance

- diagnosis depends on the passage of large volumes of diluted urine, episodes of hypernatraemia and unresponsiveness to administration of ADDVP

- this disorder is now recognised as being associated with intracranial calcification and brain damage. Early diagnosis and treatment may avoid such serious complications 
A high index of suspicion should be kept for this disorder, prompting early diagnosis and treatment in order to prevent brain damage.

\section{Final diagnosis}

Primary nephrogenic diabetes insipidus with intracranial calcification

1 McKusick VA. X chromosome phenotypes. In: McKusick VA, ed, Mendelian inheritance in man. Baltimore: Johns Hopkins University Press, 1994; p 2344.

2 McKusick VA. Autosomal recessive phenotypes. In: $\mathrm{McKu}-$ sick VA, ed, Mendelain inheritance in man. Baltimore: Johns Hopkins University Press, 1994; p 1760

3 Aicardi J, ed. Textbook of diseases of the nervous system in childhood. London: Mac Keith Press, 1992; pp 544-5.

4 Tohyama J, Inagaki $M$, Koeda $K$, Ohno K, Takeshita K. Intracranial calcification in siblings with nephrogenic diabetes insipidus: CT and MRI. Neuroradiology 1993; 35: $553-5$.
Keywords: nephrogenic diabetes insipidus, hypernatraemic dehydration, intracranial calcification
5 Nozue T, Uemasu F, Endoh H, Sako A, Takagi Y. Intracranial calcification associated with nephrogenic diabetes insipidus. Pediatr Nephrol 1993; 7: 74-6.

6 Macauly D, Watson M. Hypernatraemia in infants as a cause of brain damage. Arch Dis Child 1967; 42: 485-91. 7 Schofer O, Beetz R, Rascher C, Schutz C, Bohal J. Nephronic diabetes insipidus and intracranial calcification. Arch Dis Child 1990; 65: 885-7.

\title{
Excess adipose and heartburn
}

\author{
WDB Clements, P Rice, C Harvey
}

A previously well 80-year-old woman presented with a three-month history of increasing epigastric discomfort, abdominal bloating, 14 pounds weight gain and heartburn. On examination she was generally well, although the upper abdomen appeared diffusely distended. There was no discrete mass or organ enlargement palpable, although the upper abdomen was dull to percussion. Haematological and serum biochemical parameters were all within normal limits and urinalysis was normal. Her chest X-ray showed a large hiatus hernia. Computed tomography (CT) scan of the abdomen was performed (figures 1 and 2).

The Mater Hospital Trust, Crumlin Road, Belfast,

N Ireland

WDB Clements

P Rice

C Harvey

Correspondence to $\mathrm{Mr}$ WDB Clements, Senior Registrar in Minimal Access Therapy, MATTU, The Royal Surrey County Hospital, Egerton Road, Guildford GU 5XX, UK

Accepted 27 June 1996

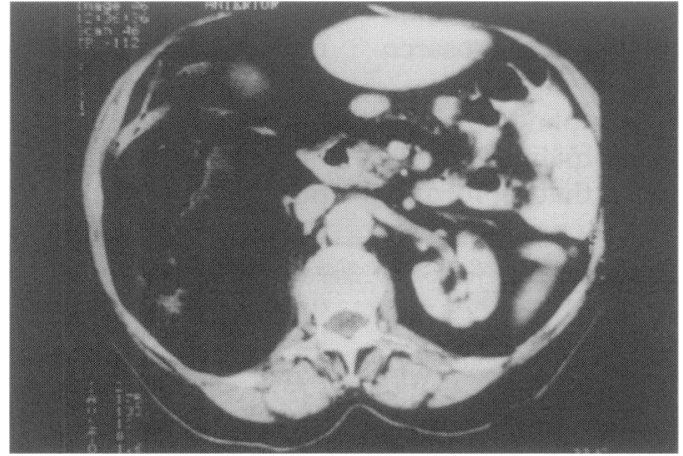

Figure 1 CT scan of abdomen

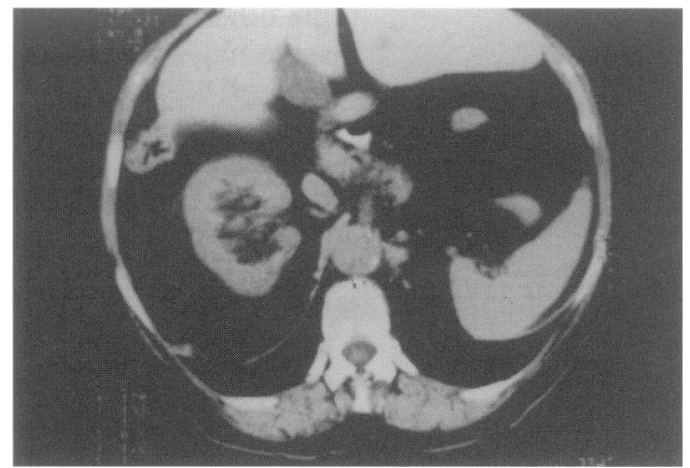

Figure 2 CT scan of abdomen

\section{Questions}

1 What abnormality is shown on the CT scan?

2 What is the most probable diagnosis? 